\title{
De Frankfurter Schule en algoritmisch bestuur*
}

\author{
Ringo Ossewaarde
}

\begin{abstract}
De Frankfurter Schule biedt een boeiende intellectuele oriëntatie voor een kritische en ontmaskerende bestuurskunde. Zij dwingt bestuurskundigen te reflecteren op de rol van bestuurskundigen in bestaande bestuurlijke processen en machtsstructuren in de technologische samenleving. In dit essay dient de ontwikkeling van algoritmisch bestuur als casus om de kritische analyse te illustreren, om daarmee de hedendaagse relevantie van de Frankfurter Schule voor een kritische bestuurskunde te benoemen. Vanuit het gedachtegoed van de Frankfurter Schule kan worden geconcludeerd dat algoritmisch bestuur een vorm van bestuur is die de status quo van de technologische samenleving bekrachtigt. Zij gaat nadrukkelijk gepaard met creativiteitsverlies, technologische dominantie, gebrek aan weerstand, en misbruik van technologie. Voor zowel bestuurskundigen als ambtenaren zijn dergelijke kritische inzichten van belang om bewust te worden binnen wat voor beleidssystemen zij werken, en hoe zij met hun werk en met nieuwe technologieën steeds weer de-humaniserende gevestigde orden dreigen te reproduceren.
\end{abstract}

\section{Inleiding}

De Frankfurter Schule biedt een boeiende intellectuele oriëntatie voor een kritische en ontmaskerende bestuurskunde (Box, 2005). Zij dwingt bestuurskundigen te reflecteren op de beleidsprocessen en bureaucratische structuren van de technologische samenleving, en de legitimerende of bekritiserende rol van bestuurskundigen daarin. Een kritische bestuurskunde die is geïnspireerd door de Frankfurter Schule, accepteert bestaande processen en structuren niet. Zij daagt deze juist uit en ontmaskert ze, uiteindelijk als kritiek op dominantie, repressie, reïficatie, eenzijdigheid, dwaling, erotisch tekort of gebrek aan creativiteit. Zij is gericht op het identificeren van alternatieve, meer humaniserende en democratiserende, toekomstpaden met behulp van dialectische verbeeldingskracht. In dit essay wordt beknopt ingegaan op de betekenis van de Frankfurter Schule voor een kritische bestuurskunde in de technologische samenleving. De ontwikkeling van algoritmisch bestuur dient als casus om de kritische analyse te illustreren, om daarmee de essentie van de Frankfurter Schule en iets van haar hedendaagse relevantie voor een kritische bestuurskunde te benoemen. Algoritmisch bestuur wordt hierbij gezien als een vorm van bestuur die bestaande beleidsprocessen en bureaucratische structuren van de technologische samenleving bekrachtigt, en daarom door kritische bestuurskundigen dient te worden ontmaskerd als een vorm van dwaling.

* Dr. Ringo Ossewaarde is als universitair hoofddocent Bestuur, Samenleving en Technologie verbonden aan de Universiteit Twente 


\section{De Frankfurter Schule en kritische bestuurskunde}

De Frankfurter Schule biedt kritische bestuurskundigen een intellectuele oriëntatie waarmee het repressieve karakter van de beleidsprocessen en bureaucratische structuren van de (industrieel) technologische samenleving kan worden blootgelegd. De kernobservatie van de Frankfurter Schule, gearticuleerd in Max Horkheimer en Theodor Adorno's 'Dialectiek van de Verlichting', is dat in de technologische samenleving beleid en bureaucratie verworden tot centrale instituties om het verlichtingsproject te organiseren. Echter, anders dan de oorspronkelijke verlichtingsdenkers beoogden met hun strijd tegen bijgeloof, vooroordelen en dogma's, hebben moderne (Newtoniaanse) techno-wetenschap en industriële technologieën niet tot het gewenste kritische denken, bevrijding en emancipatie geleid. Integendeel, techno-wetenschap en technologie hebben juist geleid tot verval van de hogere culturele waarden en hun tradities en daarmee een culturele crisis gecreëerd waarin de meest geavanceerde brute repressie zich heeft kunnen ontwikkelen. Voor de Frankfurter Schule uit techno-wetenschappelijke verlichtingskennis zich in bestuurlijke technieken en beleidsinstrumenten waarmee een geconcentreerde agressiviteit jegens de natuur, volkeren of wereld wordt voortgezet. Günther Anders benadrukt dat de atoombom - met haar technologische potentie om de hele wereld op te blazen en de natuur te vernietigen - ontstond in een wetenschappelijk laboratorium. En deze was een onderdeel van een beleidsprogramma - het Manhattanproject als uitdrukking van het verlichtingsproject in de technologische samenleving - waardoor de atoomboom dus ook vooral het resultaat is van bestuurskundige kennis van coördinatie. Hetzelfde kan worden gesteld over concentratiekampen, de organisatie van genociden, de plunderingen van natuurlijke hulpbronnen in de Global South, de aanpak van de klimaatcrisis, Fort Europa, et cetera.

Hoe komt het dat de alliantie tussen beleid, bureaucratie, wetenschap, technologie en industrie in de technologische samenleving bovenal repressief bestuur genereert? De duiding van de Frankfurter Schule is met name geïnspireerd door Nietzsche. Voor de Frankfurter Schule is de industrialisering van het verlichtingsproject in de (industrieel) technologische samenleving het kernprobleem. Door de industrialisering van het verlichtingsproject wordt kennis technisch, instrumenteel, objectiverend en onkritisch. Zij wordt 'eendimensionaal', in de termen van Marcuse (1970). De industrialisering van deze verlichtingsvariant koppelt het verlichtingsproject los van de oorspronkelijke emancipatoire doelen van de verlichting. In dit eendimensionale, geïnstrumentaliseerde denken worden contradicties en spanningsvelden (tussen politici en ambtenaren, managers en professionals, ambtenaren en burgers, overheid en bedrijven) eenduidig gemodelleerd. Aspecten van de menselijke ervaring die niet systematisch of beheersbaar zijn - die onbepaald, speels, imaginair en sensueel zijn - worden weggemoffeld in abstracte modellen. De geest, afgeleid van het oud-Griekse nous zoals door Socrates begrepen - waarmee de Frankfurter Schule verwijst naar verbeelding, geweten, bewustzijn, verwondering, poëtische verfijning, denkkracht en potente scheppingskracht - wordt in dit geïndustrialiseerde verlichtingsdenken nadrukke- 
lijk verzaakt, tot het punt dat hij te zwak is om agressie en vernietigingskracht te remmen. Kortom, volgens de Frankfurter Schule hangt de ontwikkeling van repressief bestuur, die zij waarneemt in zowel gewelddadige totalitaire als meer liberale overheden, nauw samen met een diepgewortelde culturele crisis die uiteindelijk wordt veroorzaakt door een vertechnologiseerd verlichtingsproject.

Met Woodrow Wilsons 'The Study of Administration' (1887) begon de bestuurskunde, als academische discipline en als democratisch project, waarbij doelmatig beleid en bureaucratie incompetent, corrupt en autocratisch bestuur teniet zouden moeten doen. Voor kritische bestuurskundigen (zoals Dwight Waldo) draait de bestuurskunde om het ontwikkelen van kennis omwille van de vorming van democratisch bestuur, waarbij democratisch bestuur uitdrukking geeft aan democratische cultuur (democratisch ethos). Horkheimer en Adorno suggereren echter dat met de ontwikkeling van een culturele crisis in de technologische samenleving bestuurskunde wordt ingebed in de oligarchische alliantie tussen beleid, bureaucratie, wetenschap, technologie en industrie. De alliantie absorbeert de bestuurskunde in haar kennissystemen, maar vermaalt haar tot een onkritisch legitimeringsapparaat - in dienst van doelmatig beleid en procedureel-rationele bureaucratie (gekenmerkt door massaproductie, standaardisatie, formalisering, specialisatie, et cetera) en losgekoppeld van democratische doelen. Een onkritische, eendimensionale bestuurskunde betekent in dit verband dat de bestuurskunde haar bestaansrecht ontleent aan haar beschrijvingen en verklaringen binnen de beleidsprocessen en bureaucratische structuren van de alliantie die de technologische samenleving vormgeeft. Vanuit het gedachtegoed van de Frankfurter Schule is een dergelijke legitimering een vorm van wetenschappelijk verraad van de verlichting. Adorno legt uit dat het niet verantwoord is om het eendimensionale verlichtingsproject, inclusief haar beleid, bureaucratie, industrie, technologie en wetenschap, te legitimeren; deze vooruitgang leidde immers tot de organisatie van de Shoah. Vanuit Adorno's negativistische gedachtegang moeten bestuurskundigen zich vooral toespitsen op negatieve verschijnselen van de ontwikkeling van de technologische samenleving. Voorbeelden van negatieve verschijnselen zijn de ontwikkeling van technische en bureaucratische systemen die, in de vorm van repressie, uitdrukking geven aan een diepgewortelde culturele crisis - een crisis die zich in het openbaar bestuur manifesteert in de vorm van de marginalisering van denkprocessen in bestuur en beleid. In lijn met Adorno's gedachtegang kan worden gesteld dat het openbaar bestuur een samenstelling is van beleid en bureaucratie die door een kritische bestuurskunde moet worden geëvalueerd in het licht van de oorspronkelijke verlichtingstoewijding aan bevrijding van ondemocratische processen en repressieve structuren.

Kortom, een kritische bestuurskunde die is geïnspireerd door de Frankfurter Schule, richt zich op het ontmaskeren van de alliantie en de vorming van de kapitalistische technologische samenleving, waarbij zij zelf buiten de kaders van de alliantie blijft (in ieder geval in intellectuele zin). Zij beschouwt overheid en wetenschap (en dus ook bestuurskundigen) hierbij bepaald niet als neutrale, laat staan onschuldige, actoren. Integendeel, overheid en wetenschap zijn bovenal, 
samen met andere machtshebbers (zoals oliebaronnen), de vormgever en handhaver van repressieve structuren. In de afgelopen decennia handhaaft de overheid dergelijke structuren bijvoorbeeld door het systematisch bekrachtigen van haar eigen eendimensionale beleidsdiscoursen (zoals discoursen over eigen verantwoordelijkheid, de participatiesamenleving, de terugtredende overheid of veerkracht), waarbij contradicties worden gemaskeerd en wezenlijke alternatieven de kop in worden gedrukt. Van ambtenaren wordt verwacht dat ze binnen de grenzen van een bekrachtigd beleidsdiscours opereren, en daarmee beleidsmatig de huidige machtsstructuren bekrachtigen. Een kritische bestuurskunde zoekt nadrukkelijk naar potentieel om aan een dergelijke verdrukking te ontsnappen, opdat daarmee ruimte voor de geest wordt gecreëerd. Het scheppen van ruimte voor de geest, en dus humanisering, is altijd het uiteindelijke doel van een kritische bestuurskunde die voortborduurt op de werken van de Frankfurter Schule.

\section{De kritische analyse van beleid en politiek}

De kritische analyse van de Frankfurter Schule legt, aan de hand van de dialectiek der verlichting - waarbij het verlichtingsproject, aanvankelijk kritisch, omslaat in repressief bestuur - de alliantie tussen beleid, bureaucratie, wetenschap, technologie en industrie bloot. Onderworpen aan de alliantie van de technologische samenleving verwordt het individu tot een (politiek, sociaal, cultureel, intellectueel, moreel) zwak, afhankelijk, onvrij, ontworteld, vervreemd wezen dat een gemakkelijke prooi is voor demagogen, technologen, managers, professionals, marketeers en de entertainmentindustrie. De Frankfurter Schule deconstrueert niet alleen de perverse actualiteit van de alliantie in de technologische samenleving. Integendeel, zij stimuleert vooral onafhankelijkheid van huidige beleidsprocessen en bureaucratische structuren die de verbeelding van democratische alternatieven en creativiteit om dergelijke alternatieven te scheppen juist de kop in drukken. De Frankfurter Schule is vooral alert op mogelijke condities, op het duiden van datgene dat nog niet is gerealiseerd, en dat de democratische potentie heeft om repressie af te wenden. Hoe repressief en technologisch dominant een actuele situatie die wordt beheerst door de alliantie er ook uit moge zien, gegeven de contradicties van de technologische samenleving bestaat altijd de mogelijkheid dat er een wezenlijke verandering optreedt richting een meer democratische samenleving. Zie hier hoe de kritische analyse van de alliantie samengaat met hoop. Dit is een hoop die voortkomt uit het onbepaalde karakter van politiek, beleid, bureaucratie en technologie.

De kritische analyse van de actualiteit in de technologische samenleving spitst zich toe op het misbruik van technologie, waarvan de gaskamers en bombardementen van Auschwitz en Hiroshima de meest extreme manifestaties zijn. Horkheimer en Adorno spreken in dit verband van de actuele situatie als 'permanente catastrofe' die bestaat uit de uitbanning van de autonomie van de gedachte, de verdrukking van de geest. In de technologische samenleving worden communicatietechnologie, zoals radio en televisie, misbruikt om propaganda, demagogie, ide- 
ologie en entertainment te verbreiden, en de geest in slaap te sussen. Horkheimer en Adorno richten zich niet alleen op totalitaire overheden die propaganda-apparaten weten te perfectioneren. In situaties die worden gekenmerkt door liberaal (of anti-totalitair) beleid opereert de cultuurindustrie, gericht op joviaal entertainment, als communicatiestructuur waarin het denkende subject wordt verslagen. Onder andere in zijn 'Hiroshima is overal' geeft Günther Anders (1982) aan dat in de technologische samenleving de zogenaamde 'Promethische discrepantie' zich openbaart, als voorbeeld van de verdrukking van de geest. De Promethische discrepantie duidt erop dat binnen de kaders van beleidsprocessen en abstracte structuren van de technologische samenleving (Anders zelf spreekt van het atoomtijdperk) het geweten, bewustzijn, denken, inbeelding en ontwikkeld gevoelsleven ontbeert om de apocalyptische gevolgen van industriële technologieën te kunnen visualiseren. Door een dergelijk intellectueel en moreel tekort blijft gevaar (voor democratie en humanisering) onzichtbaar en verdwijnt bestuurlijke verantwoordelijkheid.

In een actuele wereld draagt industriële (bovenal nucleaire) technologie catastrofale (bijvoorbeeld ecologische en genocidale) gevolgen in zich. Volgens de Frankfurter Schule is de technologische samenleving zoals die wordt vormgegeven door de alliantie een (zowel actueel als potentieel) catastrofale samenleving. Veiligheid, banen, carrières, wetenschap, communicatie en consumptie zijn afhankelijk van technologie, terwijl deze vrede en welvaart samengaan met plundering van grondstoffen, vervuiling, vernietiging van inheemse bevolkingen, dreiging van nucleaire conflicten, et cetera. Maar met haar dialectische verbeelding benadrukt de Frankfurter Schule dat in de huidige situatie de historische mogelijkheid bestaat om een andersoortige relatie tot technologie te kweken; en daarmee los te komen uit de greep van de alliantie. Met name Herbert Marcuse, in 'Eros en cultuur', ziet in technologie een mogelijk bevrijdingspotentieel. Als we beschouwen hoe effectief de alliantie is in het kanaliseren van lichamelijke energie en creativiteit voor productiedoeleinden, waarbij het disruptieve potentieel van scheppingskracht structureel de kop in wordt gedrukt, dan is zo'n mogelijke nieuwe situatie van vrijheid om iets nieuws te scheppen nauwelijks nog voor te stellen. Marcuse meent echter dat als door automatisering machines arbeid overnemen, er een historische mogelijkheid ontstaat om aan de conditionering en prestatietucht van het gemechaniseerde arbeidsproces te ontsnappen. Marcuse beeldt zich daarbij in wat deze ontsnappingsroute zou impliceren voor de geest, in het bijzonder voor potente scheppingskracht, speelsheid, vitaliteit, verrukking, emotionele verfijning en verlangen naar een andere (minder repressieve, meer democratische) situatie. De robotisering van de arbeidsmarkt biedt volgens Marcuses utopische gedachtegang een historische mogelijkheid voor het ontsnappen aan de grip van de alliantie.

\section{De eendimensionaliteit van algoritmisch bestuur}

Voor een kritische bestuurskunde die wordt geïnspireerd door de intellectuele oriëntatie van de Frankfurter Schule, vormt de alliantie die de technologische 
samenleving vormgeeft een probleem voor het denken en voor de scheppingskracht. In de hedendaagse technologische samenleving die wordt gekenmerkt door een zogenaamde AI-revolutie - een update van het laatste verlichtingsproject - dreigt het openbaar bestuur zelf te automatiseren, in de vorm van algoritmisch bestuur. Dit is een vorm van geautomatiseerd bestuur waarbij kunstmatige intelligentie wordt ingebed in beleidsprocessen en bureaucratische structuren zoals bijvoorbeeld in juridische processen, het uitvoeren van de sociale zekerheid, of in politiewerk. Bij algoritmisch bestuur worden modellering, technieken en technologieën van de computerwetenschap toegepast om besluiten en beleidstaken te automatiseren, in de zoektocht naar verdere mechanisering (en daarmee doelmatigheid, kracht, snelheid, calculatie, precisie) van de wereld. Henry Kissinger (2018) duidt dit mechaniseringsproces als het 'einde van de verlichting'. AI, stelt Kissinger, dooft de geest. Zij dooft de contemplatie, introspectie, dialoog, creativiteit en verbeelding die denkprocessen kenmerken; en zij vervangt deze door rekenkracht en instrumentaliteit. Op soortgelijke wijze duidt algoritmisch bestuur vanuit het perspectief van de Frankfurter Schule op een continuering van het eendimensionale, gematerialiseerde, geobjectiveerde verlichtingsproject, waarbij bestaande beleidsprocessen en bureaucratische structuren worden gereïficeerd en alternatieven worden weggedrukt. In haar technologiekritiek wijst de Frankfurter Schule op het bijgeloof en de mythen van de technologische samenleving: ondanks de permanente catastrofe worden technische systemen aanbeden.

Het grote pijnpunt van algoritmisch bestuur zit hem voor een kritische bestuurskunde niet primair in de ethiek van AI, in de problemen van mensenrechtenschendingen (met name privacy), de ondoorzichtigheid van (en onbekendheid met) algoritmen, de machtsconcentratie (en machtsmisbruik) van de alliantie van zowel overheden als tech-oligarchen zoals Google en Amazon. Voor een kritische bestuurskunde is het probleem van algoritmisch bestuur veel extremer van aard: algoritmisch bestuur is een hedendaagse uitdrukking van de cultuurcrisis in de technologische samenleving die de Frankfurter Schule duidt. Cathy O'Neil (2016) spreekt in dit verband van weapons of math destruction: algoritmen, data en wiskunde zijn nimmer neutraal, maar zijn verworden tot wapens binnen de gevestigde alliantie waarmee gevestigde, bovenal kapitalistische, belangen worden bekrachtigd. AI bekrachtigt eendimensionale structuren van technologische dominantie. In de taal van Anders (1956) kan algoritmisch bestuur worden geduid als apocalyptisch bestuur - bestuur dat de geest verdringt met bureaucratisch-technische systemen en dat de Promethische discrepantie bekrachtigt, waardoor de apocalyptische gevolgen van AI niet kunnen worden voorgesteld en voorspeld. Op dit moment is AI, vooral door enorme dataproductie, bij uitstek een voorbeeld van een snelle technologische ontwikkeling die sneller gaat dan de ontwikkeling van verbeeldingskracht en geweten. Van AI wordt verwacht dat zij problemen gaat oplossen waar politici, bestuurders en burgers falen. Bij algoritmisch bestuur wordt bestuurlijke verantwoordelijkheid voor kennis, technieken en technologieën toegekend aan gezichtsloze AI-producenten en adviseurs en aan de technologie (AI) zelf. Niemand is verantwoordelijk voor AI en iedere stakehol- 
der - van producent tot ambtenaar - doet slechts zijn werk in de technologische samenleving. De levens van medewerkers - zoals ambtenaren - worden voortgestuwd aan de hand van de ritmen van een gemechaniseerd beleidsproces dat van ambtenaren conformisme en repressie van creatieve vermogens vereist. In het algoritmisch tijdperk wordt van ons allemaal verwacht dat we ons aanpassen om algoritmische machines hun werk te laten doen. Om dit mogelijk te maken wijzen politici en beleidsmakers in hun recent gepubliceerde AI-strategieën op de noodzaak van een herstructurering van het arbeidspotentieel: alles en iedereen moet in dienst worden gesteld van AI, de nieuwste fetisj.

Een kritische bestuurskunde beschouwt algoritmisch bestuur als geavanceerde bekrachtiging van het eendimensionale denken, bron van catastrofen in de technologische samenleving. In de technologische samenleving van vandaag, met haar mythen en bijgeloof, hebben algoritmen en AI een magische aantrekkingskracht, terwijl de menselijke geest - en in bredere zin de menselijke waardigheid - wordt gedevalueerd en gewantrouwd. Ook al is voor bestuurskundigen bekend dat de implementatie van AI in overheidsorganisaties - gekenmerkt door bureaucratische politiek, incrementalisme, doormodderen - rommelig is en voortdurend dreigt te mislukken, het magische geloof in AI als oplossingsmachine blijft recht overeind. Zo ook in het recente 'Strategisch Actieplan voor Artificiële Intelligentie' (oktober 2019) van de Nederlandse overheid, waarin verlossing wordt verwacht van AI: niet politiek en bestuur maar AI zal problemen oplossen. Gegeven het actuele, op macht gerichte, verlichtingsdenken worden algoritmen vooral door overheden voorgesteld als een hoogtepunt van rationeel bestuur, terwijl ze, ingebed in bestaande beleidsprocessen en bureaucratische structuren, bovenal een verdrukkende en repressieve werking hebben. Algoritmisch bestuur is een politiek-bestuurlijk, ofwel technocratisch, verschijnsel: met behulp van algoritmen bekrachtigt de alliantie de permanente catastrofe (ecologisch, genocidaal, et cetera) van de technologische samenleving. Dit betekent dat AI niet los kan worden gezien van bestaande machtsverhoudingen, waarbinnen wordt gezocht naar nieuwe ruimtes voor objectivering, rekenkracht en de bureaucratische perfectie. Echter, Marcuse benadrukt dat er met automatisering ook een mogelijkheid kan ontstaan om aan gemechaniseerde arbeidsprocessen en bureaucratische tucht te ontsnappen. Algoritmisch bestuur zou vanuit die meer optimistische gedachtegang de mogelijkheid kunnen bieden om politiek-bestuurlijke energie te richten op de meer wezenlijke verschijnselen - zaken die niet zijn te mechaniseren, zoals het bestuurlijk scheppen van ruimte voor de geest en het revitaliseren van een democratisch ethos.

\section{Conclusie}

De Frankfurter Schule is een boeiende intellectuele stroming die kritische bestuurskundigen leert dat de technologische samenleving zich voortbeweegt volgens een perverse dialectiek van de verlichting, waarbij de oorspronkelijke culturele idealen van het verlichtingsproject worden verraden. De zogenaamde 
'AI-revolutie' kan worden geduid als een voortzetten van dat geperverteerde verlichtingsproject. Het kritische van een kritische bestuurskunde zit hem enerzijds in haar analyse van eendimensionaal denken. Dit soort denken wordt bekrachtigd in bureaucratische structuren en technische systemen zoals AI. Zij gaat gepaard met verzwakking, creativiteitsverlies, technologische dominantie, gebrek aan weerstand, en misbruik van technologie. Anderzijds leert zij dat kennis die de potentie heeft om tot bevrijding uit een dergelijke catastrofale situatie te leiden tweedimensionaal of dialectisch is. Dit impliceert dat een kritisch bestuurskundige denkt in termen van contradicties en de mogelijke openingen voor wezenlijke veranderingen die kunnen ontstaan als contradicties schuren. Voor de kritische analyse van politiek en beleid betekent dit dat de Frankfurter Schule de huidige gevestigde orde van de kapitalistische technologische samenleving - gekenmerkt door de alliantie tussen beleid, bureaucratie, wetenschap, technologie en industrie - radicaal in twijfel trekt en deze de-legitimeert. Voor zowel bestuurskundigen als ambtenaren zijn dergelijke kritische inzichten van belang om zich bewust te worden binnen wat voor soort beleidssysteem zij werken, en hoe zij met hun werk en met nieuwe technologieën steeds maar weer gevestigde beleidsprocessen en bureaucratische structuren dreigen te reproduceren, tenzij zij los weten te komen van de alliantie.

\section{Literatuur}

Anders, G. (1956). The obsolescence of man, Volume II: On the destruction of life in the epoch of the third industrial revolution. Verkregen van https://libcom.org/files/Obsolescenceof ManVol\%20IIGunther\%20Anders.pdf

Anders, G. (1982). Hiroshima is overal. Verkregen van https://bosjananne.wordpress.com/ teksten-van-en-over-gunther-anders/hiroshima-is-overal-voorwoord/

Box, R.C. (2005). Critical social theory in public administration. London: M.E. Sharpe.

Horkheimer, M., \& Adorno, T.W. (2007). Dialectiek van de verlichting: Filosofische fragmenten. Amsterdam: Boom.

Kissinger, H. (2018, June). How the enlightenment ends. The Atlantic, https:// www.theatlantic.com/magazine/archive/2018/06/henry-kissinger-ai-could-mean-theend-of-human-history/559124/

Marcuse, H. (1970). De eendimensionale mens. Bussum: Brand.

Marcuse, H. (1996). Eros en cultuur. Utrecht: Bijleveld.

O'Neil, C. (2016). Weapons of math destruction: How big data increases inequality and threatens democracy. New York: Crown.

Wilson, W. (1887) The study of administration. Political Science Quarterly 2(2): 197-222. 